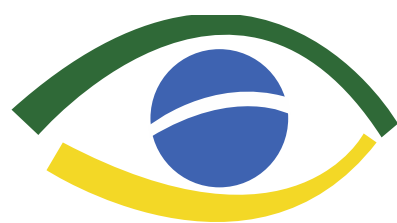

\section{Observatório da Jurisoliçãc Constitucional}

Observatório da Jurisdição Constitucional. Ano 7, no. 1, jan./jun. 2014. ISSN 1982-4564.

\title{
Reflexões sobre a liberdade de manifestação: funções, âmbito, conteúdo e limites
}

José Melo Alexandrino

Resumo: A partir dos dados do Direito português, mas a pensar em ordenamentos como o brasileiro, onde esse direito fundamental não foi objecto de consagração expressa, o artigo ocupa-se do recorte técnicojurídico da liberdade de manifestação. Para o efeito, começa por identificar as respectivas funções, jurídicas e extra-jurídicas, procurando esclarecer em seguida o âmbito de protecção, o conteúdo e os limites desse jovem e vigoroso direito fundamental, bem como as perturbações (afectações) a que o mesmo pode estar sujeito num sistema de Estado constitucional.

Palavras-chave: liberdade de manifestação; funções do direito fundamental; âmbito de proteção, limites e afectações.

\begin{abstract}
Considering the express provision of the Portuguese law and the implicit prescription of the Brazilian law, the paper deals with the legal framework of freedom of demonstration, discussing the function, the scope of protection, the content and the limits of this young and vigorous fundamental right in the context of the Constitutional State.
\end{abstract}

Keywords: freedom of demonstration, functions, scope of protection, limits and affectations of this fundamental right.

\footnotetext{
* Professor da Faculdade de Direito da Universidade de Lisboa, Mestre e Doutor em Direito, Investigador do Centro de Investigação de Direito Público do Instituto de Ciências Jurídico-Políticas da mesma Faculdade (CIDP).
} 


\section{Introdução}

O direito (ou liberdade) de manifestação é um jovem e vigoroso direito fundamental: jovem, na medida em que surge apenas no século $\mathrm{XX}$, de certo modo já como um fruto do constitucionalismo democrático do pós-guerra, razão pela qual o mesmo não aparece expressamente na maioria das Constituições - Espanha e Portugal são aí a excepção, ao passo que o Brasil é a regra ${ }^{1}$; mas é também vigoroso, quer por comparação com o seu ascendente materno (a velha liberdade de reunião) ${ }^{2}$, quer pelas relações privilegiadas que mantém com a figura cimeira da liberdade de expressão ${ }^{3}$, quer por via das funções especiais que está destinado a servir e pela vitalidade que revela neste início do século $\mathrm{XXI}^{4}$.

A partir dos dados do ordenamento português ${ }^{5}$, o meu propósito é o de tentar percorrer algumas questões que se colocam no recorte técnico-jurídico da figura, dividindo a exposição em quatro breves tópicos: as funções, o âmbito de protecção, o conteúdo e os limites e afectações do direito de manifestação.

\section{As funções (extra-jurídicas) especiais do direito de manifestação}

Não é difícil apreender o papel que este formidável direito fundamental tem desempenhado e está destinado a desempenhar no nosso tempo: escusaria por isso de lembrar aqui manifestações como as de 11 de Setembro de 2012 na Catalunha, de 15 de Setembro de

\footnotetext{
${ }^{1}$ Os artigos $45 .^{\circ}$, n. $^{\circ}$ 2, da Constituição portuguesa de 1976 e 21. ${ }^{\circ}$, n. ${ }^{\circ}$ 2, da Constituição espanhola de 1978 consagram expressamente o direito de manifestação, ao lado do direito de reunião, ao passo que o artigo $5 .^{\circ}$, inciso XVI, da Constituição federal brasileira de 1988 - como a generalidade das Constituições - apenas se refere ao direito de reunião.

${ }^{2}$ A propósito desta vitalidade, Sérvulo Correia, Direito de Manifestação - âmbito de protecção e restrições, Coimbra, 2006, p. 16.

${ }^{3}$ Sobre a importância deste direito, por último, José Melo Alexandrino, «O âmbito constitucionalmente protegido da liberdade de expressão», in AAVV, Media, Direito e Democracia - I Curso pós-graduado em Direito da Comunicação, Coimbra, 2014, pp. 41 ss. [no prelo].

${ }^{4}$ Ainda que tenha diminuído em $6 \%$ face a 2012, segundo o último Relatório Anual de Segurança Interna, realizaram-se no ano de 2013 em Portugal 2859 manifestações (com indicações, http://economico.sapo.pt/noticias/numero-de-manifestacoes-esta-a-diminuir_190263.html).

${ }^{5}$ Dados que, salvo o Brasil, alcançaram todos os demais ordenamentos constitucionais de língua portuguesa (assim, artigo 34. ${ }^{\circ}$, n. $^{\circ}$ 2, da Constituição são-tomense de 1990 , artigo $53 .^{\circ}$, n. $^{\text {os }} 2$ e 3 , da Constituição caboverdiana de 1992, artigo 54. ${ }^{\circ}$, n. ${ }^{\circ}$ 2, da Constituição da Guiné-Bissau de 1993, artigo 27..$^{\circ}$ da Lei Básica da Região Administrativa Especial de Macau de 1993, artigo 42. ${ }^{\circ}$, n. ${ }^{\circ}$ 2, da Constituição de Timor-Leste de 2002, artigo 51..$^{\circ}$ da Constituição moçambicana de 2004 e artigo 47. ${ }^{\circ}$ da Constituição angolana de 2010).
} 
2012 em Portugal (“Que se lixe a troika! Queremos as nossas vidas!”), as “jornadas de junho" de 2013 no Brasil ou as dramáticas manifestações já deste ano na capital da Ucrânia.

Além de cumprir as tradicionais funções jurídicas que lhe estão reservadas (de defesa, de protecção e de não discriminação), bem como a não menos clássica função sociológica (de distância entre o Estado e as pessoas) ${ }^{6}$, o direito de manifestação destaca-se por cumprir pelo menos duas funções extra-jurídicas especiais: a de constituir uma particular estrutura comunicativa e a de constituir um sensor do regime político (ou forma de governo) efectivamente existente:

(i) Como estrutura comunicativa ${ }^{7}$ (verdadeiro elemento da formação da opinião pública, que nem por isso afecta a sua essencial dimensão subjectiva), o direito de manifestação é, por um lado, um instrumento "de expressão" simultaneamente individual e colectiva de opiniões e ideias ${ }^{8}$ e, por outro, um instrumento "de compensação" do défice de participação política (nos regimes autoritários) ou do défice de representação (nos regimes pluralistas) ${ }^{10}$;

(ii) Por sua vez, como sensor do regime político, da presença ou da ausência do direito de manifestação, da forma como é regulado (com ou sem regime preventivo) e da forma como o respectivo exercício é protegido, tolerado ou reprimido (com ou sem respeito pelos princípios do Estado de Direito), é relativamente fácil intuir a natureza de um regime político em concreto ${ }^{11}$.

\footnotetext{
${ }^{6}$ Para uma reiterada adesão ao ponto de vista (luhmanniano) segundo o qual "os direitos fundamentais têm por função assegurar a diferenciação, ou seja, a distância entre o Estado e as pessoas”, José Melo Alexandrino, $O$ sistema de direitos fundamentais na Lei Básica da Região Administrativa Especial de Macau, Macau, 2013, p. 17.

${ }^{7}$ João Paulo Miranda de Sousa, «O direito de manifestação», in Boletim do Ministério da Justiça, n. 375 (1988), p. 8; Sérvulo Correia, Direito de Manifestação..., p. 17; J. J. Gomes Canotilho / Vital Moreira, Constituição da República Portuguesa Anotada, vol. I, 4. ${ }^{\text {a }}$ ed., Coimbra, 2007, p. 936; Jorge Miranda, «Artigo 45. ${ }^{\circ}$, in Jorge Miranda / Rui Medeiros, Constituição Portuguesa Anotada, 2. ${ }^{a}$ ed., Coimbra, 2010, p. 946.

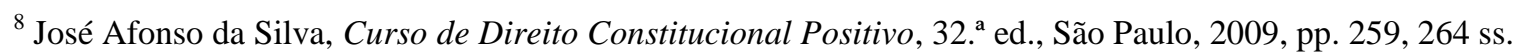

9 A cargo normalmente, mas não necessariamente, dos grupos mais fracos (enfaticamente, Eduardo Correia Baptista, Os direitos de reunião e manifestação no Direito português, Coimbra, 2006, p. 74).

${ }^{10}$ José Melo Alexandrino, «Democracia representativa e democracia participativa na União Europeia», in Elementos de Direito Público Lusófono, Coimbra, 2011, pp. 228 ss.

11 António Francisco de Sousa, «Liberdade de Reunião e de Manifestação no Estado de Direito»,in Direitos Fundamentais \& Justiça, ano 6, n. 21 (out dez 2012) pp. 27 ss.; no âmbito da Ciência política, distinguindo entre regimes totalitários, autoritários, democráticos e teocráticos, por último, Luís Pereira Coutinho, Teoria dos Regimes Políticos, Lisboa, 2013.
} 


\section{O âmbito de protecção do direito de manifestação}

Na Constituição de 1976 (e nas dos demais ordenamentos de língua portuguesa) ${ }^{12}$, tudo aponta a que a manifestação deva ser entendida como uma "reunião qualificada" 13 , observação que conduz às nossas primeiras questões: qual é a esfera da realidade (Lebensbereich) que está em causa no direito de manifestação? Qual é o âmbito de protecção (Schutzbereich) deste direito? Constituirá a licitude um requisito intrínseco do direito de manifestação?

A primeira pergunta conduz-nos à descrição de uma realidade da vida, a segunda à determinação do bem ou do interesse protegido pela norma, a terceira ao recorte dos limites do direito que se extraem por interpretação da norma constitucional.

2.1. Sendo ainda uma reunião, por manifestação deve entender-se, desde logo, seguindo essencialmente aqui a lição do Professor Jorge Miranda ${ }^{14}$ :

- Uma aglomeração de duas ou mais pessoas ${ }^{15}$;

- Uma aglomeração que não seja puramente fortuita ou ocasional;

- Uma aglomeração com vista a certos fins livremente assumidos;

- Uma aglomeração para fins assumidos em comum;

- Uma aglomeração para fins autónomos;

- Uma aglomeração por certo tempo;

- Uma aglomeração não institucionalizada ou não permanente.

\footnotetext{
${ }^{12}$ Apesar de não estar expressamente autonomizado no texto da Constituição, por maioria de razão, também no Brasil o direito de manifestação deve ser tido como um subcaso da liberdade de reunião (por todos, identificando diversas formas de manifestação, Fernando Dias Menezes de Almeida, Liberdade de Reunião, São Paulo, 2001, pp. 160 ss.).

13 Apesar de algumas vozes em sentido contrário (especialmente Eduardo Correia Baptista, Os direitos de reunião e manifestação..., pp. 9 ss.), são, a nosso ver, suficientemente indicativos a letra e a articulação sistemática dos correspondentes preceitos, o elemento histórico e genético (Diário da Assembleia Constituinte, n. ${ }^{\circ} 41$, de 3 de Setembro de 1975, pp. 1161 ss.), mas ainda o elemento lógico (Sérvulo Correia, Direito de Manifestação..., p. 35) e o facto de o manifestante solitário beneficiar directamente da protecção de um direito fundamental consideravelmente mais forte, a liberdade de expressão do pensamento (por conhecer menores limites e por estar sujeito a menores hipóteses de restrição), sem que deva excluir-se, na improvável hipótese contrária, que ainda possa e deva beneficiar dos efeitos de protecção oferecidos pelo direito de manifestação.

${ }^{14}$ Jorge Miranda, «Artigo 45. ${ }^{\circ} »$, pp. 943-944.

${ }^{15} \mathrm{Na}$ doutrina portuguesa, entre outros, J. J. Gomes Canotilho / Vital Moreira, Constituição..., I, p. 937; na doutrina brasileira, Fernando Dias Menezes de Almeida, Liberdade de Reunião, p. 145; Dimitri Dimoulis, «Artigo 5. ${ }^{\circ}$, inciso XVI», in Paulo Bonavides / Jorge Miranda / Walber de Moura Agra (coords.), Comentários à Constituição Federal de 1988, Rio de Janeiro, 2009, p. 130; Gilmar Ferreira Mendes / Paulo Gustavo Gonet

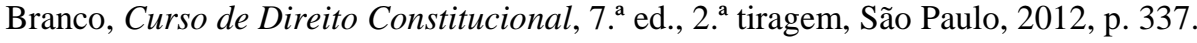


Sendo estes os traços que definem o conceito de reunião, ainda segundo Jorge Miranda, a manifestação é uma reunião qualificada em virtude dos seguintes elementos ${ }^{16}$ :

(i) Pela sua função comunicativa;

(ii) Pela vontade de dirigir uma mensagem comum à opinião pública (ou a terceiros);

(iii) Por nela estar implicada a reunião, mas também a expressão do pensamento;

(iv) Por se efectuar em lugar público (ou aberto ao público);

(v) Por se poder desenvolver tanto num local como em movimento ${ }^{17}$, em terra ou na água.

2.2. A Constituição portuguesa consagra um âmbito de protecção ${ }^{18}$ alargado do direito de manifestação, impondo apenas os requisitos (1) do carácter pacífico e (2) sem armas; já na Constituição brasileira, acrescem os requisitos (3) da não frustração de outra reunião anteriormente convocada para o mesmo local e (4) a exigência do aviso prévio.

2.3. Apesar dos muitos problemas que suscitam, estando cada um destes requisitos suficientemente trabalhado, passo de imediato à questão de saber se, como defende uma boa parte da doutrina brasileira e a praxis portuguesa, a licitude (dos fins ou das formas) deve ou não ser considerada requisito constitucional da liberdade de manifestação.

Teve fundamento constitucional a proibição da "marcha da maconha" em 2008?

A resposta dada pela generalidade da doutrina portuguesa, mas também por alguma doutrina brasileira ${ }^{19}$ é a de que um tal estreitamento da liberdade de reunião, a menos que se admitisse a indefensável doutrina dos limites imanentes, é incompatível com a formulação do direito e com a sua configuração como garantia forte ao serviço da liberdade da pessoa.

2.4. No final, segundo Sérvulo Correia, para a Constituição portuguesa, "manifestação é uma reunião, num lugar público, feita pacificamente e sem armas, que poderá ser

\footnotetext{
${ }^{16}$ Jorge Miranda, «Artigo 45. ${ }^{\star} »$, p. 945.

${ }^{17}$ Excluindo este elemento, Sérvulo Correia, Direito de Manifestação..., p. 52.

${ }^{18}$ Sobre o conceito de âmbito de protecção, Sérvulo Correia, Direito de Manifestação..., pp. 31 ss.; Dimitri Dimoulis, «Artigo 5. ${ }^{\circ}$, inciso XVI», pp. 130 ss.

${ }^{19}$ Dimitri Dimoulis, «Artigo 5. ${ }^{\circ}$, inciso XVI», p. 133.
} 
submetida a um regime mais restritivo do que o das outras reuniões" ${ }^{20}$. Quanto ao mais, estamos diante de um direito de titularidade e de essência individual ${ }^{21}$, ainda que de exercício conjunto $^{22}$, de um direito referido a acções (por oposição aos direitos referidos a estados e situações) e de um direito necessariamente complexo.

\section{O conteúdo do direito de manifestação}

Tal como sucede com os demais direitos fundamentais, o direito de manifestação surge na Constituição como uma estrutura complexa que compreende dentro de si um conjunto de direitos ou pretensões jurídicas menores, ou seja, surge nas vestes de "direito fundamental como um todo",23.

Sendo, deste modo, o direito fundamental um "feixe de poderes, posições ou faculdades disponibilizados pela norma", em termos muito sintéticos, poderemos responder que o conteúdo do direito de manifestação compreende as seguintes quatro posições fundamentais ${ }^{24}$ :

(i) O poder de convocar, promover ou aderir a uma manifestação;

(ii) A liberdade de se manifestar ou de não se manifestar (liberdade de manifestação negativa);

(iii) Um direito negativo, o de não ser impedido de se manifestar (ou seja, de participar na manifestação), envolvendo a inerente determinação da forma, das finalidades, da hora e do local da acção, bem como a utilização dos locais e das vias públicas;

(iv) Um direito de protecção contra ofensas provenientes de terceiros ${ }^{25}$.

\footnotetext{
${ }^{20}$ Sérvulo Correia, Direito de Manifestação..., p. 36 - numa formulação mais restritiva, ibidem, p. 59.

${ }^{21}$ Sérvulo Correia, Direito de Manifestação..., p. 49.

${ }^{22}$ Sérvulo Correia, Direito de Manifestação..., pp. 37, 49.

${ }^{23}$ Sérvulo Correia, Direito de Manifestação..., p. 50.

${ }^{24}$ Sobre o sentido dos correspondentes conceitos básicos, José Melo Alexandrino, Direitos Fundamentais Introdução Geral, 2. ${ }^{\text {a }}$ ed., Cascais, 2011, p. 30.

${ }^{25}$ Uma prova do interesse da identificação do conteúdo do direito reside no facto de, quanto à respectiva titularidade por pessoas colectivas - problema relativamente ao qual a doutrina se divide (para uma resposta afirmativa, J. J. Gomes Canotilho / Vital Moreira, Constituição..., I, p. 641; para uma resposta negativa, Dimitri Dimoulis, «Artigo 5. ${ }^{\circ}$, inciso XVI», p. 135) -, as mesmas serem também beneficiárias do poder, mas já não das demais componentes do direito de manifestação, que respeitam à garantia de acções individuais (também neste sentido, Eduardo Correia Baptista, Os direitos de reunião e manifestação..., p. 91; Jorge Miranda, «Artigo 45. ${ }^{\circ} »$, p. 947).
} 
Já na perspectiva do destinatário da norma, além da sujeição (ao poder ou competência do cidadão) e da adstrição ao não impedimento das acções, o conteúdo do direito traduz-se especialmente para o Estado em (1) deveres de respeito, (2) em deveres de protecção $^{26} \mathrm{e}$ (3) em eventuais deveres de provisão do acesso a lugares e espaços públicos ${ }^{27}$.

\section{Limites e afectações}

$\mathrm{Na}$ complexa matéria dos limites e das afectações (entendidas estas como qualquer prejuízo que possa perturbar a liberdade $)^{28}$, partindo da distinção entre limites $^{29}$, restrições $^{30} \mathrm{e}$ intervenções restritivas $^{31}$, podemos colocar questões como estas: quais são os limites do direito de manifestação? Será nesse plano constitucionalmente admissível a proibição do uso de máscaras em manifestações? São admissíveis restrições legislativas que não estejam expressamente previstas? É possível a interdição, a interrupção ou a dispersão de uma manifestação? Por fim, poderá uma manifestação ser proibida pelo facto de não satisfazer os requisitos constitucionais?

4.1. Na Constituição portuguesa o único limite (directo) do direito de manifestação é o requisito do carácter pacífico e sem $\operatorname{armas}^{32}$, razão pela qual a exigência de aviso prévio (Anmeldung) traduz não um limite (como o é ainda na Constituição brasileira), mas uma

\footnotetext{
${ }^{26}$ Entre outros, Eduardo Correia Baptista, Os direitos de reunião e manifestação..., pp. 91 ss.; Sérvulo Correia, Direito de Manifestação..., pp. 53 ss.; Jorge Reis Novais, Direitos Sociais - Teoria jurídica dos direitos sociais enquanto direitos fundamentais, Coimbra, 2010, pp. 257 ss.; Jorge Silva Sampaio, O dever de protecção policial de direitos, liberdades e garantias, Coimbra, 2012, pp. 90 ss.

${ }^{27}$ Jorge Miranda, «Artigo 45. ${ }^{\circ} »$, p. 948.

${ }^{28}$ Para uma sistemática geral da matéria, José de Melo Alexandrino, A estruturação do sistema de direitos, liberdades e garantias na Constituição portuguesa, vol. II - A construção dogmática, Coimbra, 2006, pp. 424 ss.; Id., «A greve dos juízes - segundo a Constituição e a dogmática constitucional», in Estudos em Homenagem ao Professor Doutor Marcello Caetano, no centenário do seu nascimento, vol. I, Lisboa, 2006, pp. 780 ss.; Id., Direitos Fundamentais..., pp. 121 ss.; na doutrina brasileira, Gilmar Ferreira Mendes / Paulo Gustavo Gonet Branco, Curso de Direito Constitucional, pp. 220 ss.

${ }^{29}$ Sobre o conceito de limite (que é sempre uma norma), José Melo Alexandrino, Direitos Fundamentais..., pp. $121 \mathrm{ss}$.

${ }^{30}$ Sobre o conceito de restrição (que é sempre uma actuação normativa), José Melo Alexandrino, Direitos Fundamentais..., pp. 123 ss.

${ }^{31}$ Sobre o conceito de intervenção restritiva (que é sempre uma actuação agressiva em concreto), José Melo Alexandrino, Direitos Fundamentais..., p. 125.

32 Já na Constituição brasileira acrescem (i) a exigência de não frustrar uma outra reunião e (ii) a exigência de “aviso prévio" à autoridade competente.
} 
"restrição" prevista da lei ${ }^{33}$, submetida por conseguinte aos requisitos constitucionais correspondentes (artigo 18. ${ }^{\circ}$ da Constituição) ${ }^{34}$.

Seja como for, é neste plano que deve ser enfrentada a questão de saber se o uso de armas defensivas (como escudos, viseiras ou máscaras) deve considerar-se protegido ou excluído do âmbito de protecção; a meu ver, a resposta é variável e dependente do contexto: tanto do contexto da manifestação em concreto $^{35}$, como do contexto relativo ao tipo de Estado: (i) num Estado constitucional que cumpre habitualmente os deveres de respeito e protecção, é razoável que não sejam permitidas armas defensivas; (ii) já num Estado autoritário (ou em processo de transição), que apresente um padrão deficiente na garantia do direito à protecção, admite-se que a pessoa possa reter nas suas mãos uma parcela razoável de decisão sobre a protecção da sua própria vida, integridade e segurança.

4.2. Quanto à possibilidade de restrições, apesar de uma certa opinião contrária presente em determinados sectores da doutrina brasileira, a resposta só pode ser afirmativa: tal como sucede com outros direitos fundamentais, o legislador democrático pode ter de editar verdadeiras leis restritivas ${ }^{36}$, para a protecção de outros valores, bens, ou interesses constitucionais primários: era esse o caso do crime de terrorismo previsto até 2003 no Código Penal português ou é ainda esse o caso das disposições que punem a participação em motim (artigos $302 .^{\circ}$ e $303 .^{\circ}$ do Código Penal) ${ }^{37}$, tal como é o caso de diversas disposições do regime do direito de reunião e de manifestação (ainda que algumas delas não passem totalmente no

\footnotetext{
33 Artigo 2. ${ }^{\text { do Decreto-Lei n. }}{ }^{\text {406/74, de }} 29$ de Agosto; no Brasil, a nível federal, rege ainda, pelo menos parcialmente, o disposto na Lei 1.207, de 25 de Outubro de 1950, estando presentemente em estudo diversas iniciativas legislativas tendentes a minorar o impacto dos previsíveis protestos por ocasião do campeonato do mundo de futebol, no Verão de 2014 - tendo provavelmente como inspiração a Lei n. ${ }^{\circ} 6.528$, de 11 de setembro de 2013, do Estado do Rio de Janeiro.

${ }^{34}$ Alguns autores vêem na exigência legal de aviso prévio mero condicionamento (cfr. Jorge Miranda, «Artigo 45. ${ }^{\circ} »$, p. 949), mas essa doutrina nem é a mais segura, nem se mostra a mais defensora do devido controlo das afectações aos direitos fundamentais; no sentido do texto, Sérvulo Correia, O Direito de Manifestação..., pp. 69 ss.; Eduardo Correia Baptista, Os direitos de reunião e manifestação..., pp. 273 ss.; ainda sobre as funções do aviso prévio, Gilmar Ferreira Mendes / Paulo Gustavo Gonet Branco, Curso de Direito Constitucional, pp. 340 s.

35 Admitindo alguma abertura na resposta, J. J. Gomes Canotilho / Vital Moreira, Constituição..., p. 639; parecendo limitar a proibição às armas com intenção de agressão, Dimitri Dimoulis, «Artigo 5. ${ }^{\circ}$, inciso XVI», p. 131; excluindo armas de qualquer natureza, Jorge Miranda, «Artigo 45. ${ }^{\circ} »$, p. 948.

${ }^{36}$ É esse também um ponto consensual no julgamento, em 28 de Junho de 2006, da Ação Direta de Inconstitucionalidade (ADI) n. 1.969 (cfr. Dimitri Dimoulis, «Artigo 5. ${ }^{\circ}$, inciso XVI», p. 137); ainda sobre essa decisão, qualificando a pretensa regulamentação como verdadeira restrição, Virgílio Afonso da Silva, Direitos Fundamentais - conteúdo essencial, restrições e eficácia, São Paulo, 2009, pp. 101 ss.

${ }^{37}$ Com entendimento diverso, Sérvulo Correia, Direito de Manifestação..., p. 58.
} 
crivo da constitucionalidade) $)^{38}$; todavia, em qualquer destas hipóteses, trata-se ainda de afectações ou ingerências que devem ser tratadas como excepção (e não como regra) e que nunca poderão considerar-se imunes a um controlo de legitimidade total.

4.3. Quanto às intervenções restritivas, cumpridas que sejam as exigências da proporcionalidade, tanto a interdição ou a interrupção de uma manifestação (nos casos expressamente previstos na lei), como o isolamento de um sector de manifestantes (quando isso seja imposto pelo cumprimento de um dever de protecção) ou a dispersão de uma manifestação (em idêntico cenário) são medidas de polícia (artigo 272. ${ }^{\circ}$ n. ${ }^{\circ}$ 2, da Constituição) $^{39}$ admitidas no ordenamento jurídico português ${ }^{40}$.

4.4. Finalmente, quanto à questão de saber como deve ser tratada uma manifestação que não satisfaça algum ou alguns dos requisitos constitucionais (como é necessariamente o caso das manifestações espontâneas no Brasil), são similares as orientações que se colhem na doutrina portuguesa e brasileira: (i) como se escreveu na ADI n. ${ }^{\circ}$ 1.969, a regra nesse domínio deve continuar a ser a de que os agentes públicos não podem, sob pena de responsabilidade criminal, "intervir, restringir, cercear ou dissolver reunião pacífica, sem armas, convocada para fim lícito" ${ }^{41}$; (ii) uma vez que a interdição e a dispersão são medidas extremas, apenas justificáveis em caso de relevante conflito concreto com outras normas de garantia de idêntica importância, faltando motivo para a proibição, a reunião deve considerar-se permitida segundo o princípio da liberdade ${ }^{42}$; (iii) no caso português, acresce o facto de o aviso prévio

\footnotetext{
${ }^{38}$ Quanto à lei portuguesa, J. J. Gomes Canotilho / Vital Moreira, Constituição..., I, p. 640; Jorge Miranda, «Artigo 45. ${ }^{\circ} »$, p. 943; quanto à lei brasileira, Fernando Menezes Dias de Almeida, Direito de Reunião, p. 107; Dimitri Dimoulis, «Artigo 5. ${ }^{\circ}$, inciso XVI», p. 136.

${ }^{39}$ Por todos, Sérvulo Correia, Direito de Manifestação..., pp. 66 ss., 95 ss.

${ }^{40}$ Interdições são facilmente concebíveis em determinadas situações de estatuto especial, particularmente à luz do artigo 270. ${ }^{\circ}$ da Constituição portuguesa (por todos, Paulo Otero, «O militares e o direito de manifestação», in Estudos jurídicos e económicos em homenagem ao Professor Doutor António de Sousa Franco, vol. III, Coimbra, 2006, pp. 599 ss.); quanto à interrupção, veja-se o disposto no artigo $5 .^{\circ}$ do Decreto-Lei n. ${ }^{\circ}$ 406/74, de 29 de Agosto; quanto à dispersão, o artigo $304^{\circ}$ do Código Penal prevê o crime de desobediência à ordem de dispersão de reunião.

${ }^{41}$ Em sentido materialmente distinto tem-se pronunciado o Conselho Consultivo da Procuradoria-Geral da República (em especial, nos Pareceres n. ${ }^{\text {ss }}$ 96/1983, de 28 de Abril de 1983, 40/1989, de 7 de Dezembro de 1989, e 83/2005, de 24 de Novembro de 2005, acessíveis a partir de www.dgsi.pt).

${ }^{42}$ Com esta lógica, Dimitri Dimoulis, «Artigo 5. ${ }^{\circ}$, inciso XVI», p. 13; Gilmar Ferreira Mendes / Paulo Gustavo Gonet Branco, Curso de Direito Constitucional, p. 341.
} 
não constituir sequer requisito constitucional $^{43}$, razão pela qual apenas a manifestação violenta ou armada extravasa do respectivo âmbito de protecção, podendo nesse caso, tal como no das manifestações que exorbitem das restrições estatutárias expressamente definidas na lei, ser proibidas e impedidas, observado que seja, mais uma vez, o princípio da legalidade e da proporcionalidade das medidas de polícia $^{44}$.

\section{Referências bibliográficas}

ALEXANDRINO, José de Melo, «A greve dos juízes - segundo a Constituição e a dogmática constitucional», in Estudos em Homenagem ao Professor Doutor Marcello Caetano, no centenário do seu nascimento, vol. I, Lisboa, 2006, pp. 747-788.

ALEXANDRINO, José de Melo, A estruturação do sistema de direitos, liberdades $e$ garantias na Constituição portuguesa, vol. II - A construção dogmática, Coimbra, 2006.

ALEXANDRINO, José Melo Alexandrino, «O âmbito constitucionalmente protegido da liberdade de expressão», in AAVV, Media, Direito e Democracia-I Curso pós-graduado em Direito da Comunicação, Coimbra, 2014, pp. 41-66 [no prelo].

ALEXANDRINO, José Melo, «Democracia representativa e democracia participativa na União Europeia», in Elementos de Direito Público Lusófono, Coimbra, 2011, pp. 223-240.

ALEXANDRINO, José Melo, Direitos Fundamentais - Introdução Geral, 2. ${ }^{a}$ ed., Cascais, 2011.

ALEXANDRINO, José Melo, O sistema de direitos fundamentais na Lei Básica da Região Administrativa Especial de Macau, Macau, 2013.

ALMEIDA, Fernando Dias Menezes de, Liberdade de Reunião, São Paulo, 2001.

BAPTISTA, Eduardo Correia, Os direitos de reunião e manifestação no Direito português, Coimbra, 2006.

BATISTA, Eduardo Correia, «O dever de realizar um aviso prévio no direito de manifestação», in Revista do Ministério Público, ano 31, n. 123 (Jul. - Set. 2010), pp. 263280.

\footnotetext{
${ }^{43}$ Sobre as consequências no ordenamento português do não cumprimento da exigência legal do aviso prévio, quando a respectiva exigência se mostre conforme à Constituição, João Paulo Miranda de Sousa, «O direito de manifestação...», pp. 17-18; Eduardo Correia Batista, Os direitos de reunião e manifestação..., pp. 284 ss.; Id., «O dever de realizar um aviso prévio no direito de manifestação», in Revista do Ministério Público, ano 31, n. ${ }^{\circ}$ 123 (Jul. - Set. 2010), pp. 263-280; J. J. Gomes Canotilho, Constituição..., I, p. 940; Jorge Miranda, «Artigo 45..$^{»}$, p. 949.

${ }^{44}$ J. J. Gomes Canotilho / Vital Moreira, Constituição..., I, p. 641.
} 
CANOTILHO, J. J. Gomes Canotilho; MOREIRA, Vital, Constituição da República Portuguesa Anotada, vol. I, 4. a ed., Coimbra, 2007.

CORREIA, Sérvulo. Direito de Manifestação - âmbito de protecção e restrições, Coimbra, 2006.

COUTINHO, Luís Pereira. Teoria dos Regimes Políticos, Lisboa, 2013.

DIMOULIS, Dimitri, «Artigo 5..$^{\circ}$, inciso XVI», in Paulo Bonavides / Jorge Miranda / Walber de Moura Agra (coords.), Comentários à Constituição Federal de 1988, Rio de Janeiro, 2009, pp. 129-137.

MENDES, Gilmar Ferreira; BRANCO, Paulo Gustavo Gonet, Curso de Direito Constitucional, 7. ${ }^{\mathrm{a}}$ ed., 2. ${ }^{\mathrm{a}}$ tiragem, São Paulo, 2012.

MIRANDA, Jorge; MEDEIROS, Rui, Constituição Portuguesa Anotada, 2. ed., Coimbra, 2010.

NOVAIS, Jorge Reis, Direitos Sociais - Teoria jurídica dos direitos sociais enquanto direitos fundamentais, Coimbra, 2010.

OTERO, Paulo, «O militares e o direito de manifestação», in Estudos jurídicos e económicos em homenagem ao Professor Doutor António de Sousa Franco, vol. III, Coimbra, 2006, pp. 599-625.

SAMPAIO, Jorge Silva, O dever de protecção policial de direitos, liberdades e garantias, Coimbra, 2012.

SILVA, José Afonso da, Curso de Direito Constitucional Positivo, 32. a ed., São Paulo, 2009.

SILVA, Virgílio Afonso da, Direitos Fundamentais - conteúdo essencial, restrições e eficácia, São Paulo, 2009.

SOUSA, António Francisco de, «Liberdade de Reunião e de Manifestação no Estado de Direito»,in Direitos Fundamentais \& Justiça, ano 6, n. ${ }^{\circ} 21$ (out dez 2012), pp. 27-38.

SOUSA, João Paulo Miranda de, «O direito de manifestação», separata do Boletim do Ministério da Justiça, n. 375 (1988).

Artigo recebido em 05 de maio de 2014. Artigo aprovado para publicação em 14 de maio de 2014.

DOI: $10.11117 / 1982-4564.07 .05$ 